\title{
Non-synonymous sequence variants within the oxygen-dependent degradation domain of the HIFIA gene are not associated with pre-eclampsia in the Finnish population
}

\author{
Sanna Heino ${ }^{1}$, Milja Kaare ${ }^{2}$, Sture Andersson ${ }^{3,4}$ and Hannele Laivuori* ${ }^{* 1,5}$
}

\begin{abstract}
Address: ${ }^{1}$ Department of Medical Genetics, Haartman Institute, FI-00014 University of Helsinki, Finland, ${ }^{2}$ Folkhälsan Institute of Genetics, FI00014 University of Helsinki, Finland, ${ }^{3}$ Hospital for Children and Adolescents, Helsinki University Central Hospital, FI-00029 Finland, ${ }^{4}$ Department of Pediatrics, FI-00014 University of Helsinki, Finland and ${ }^{5}$ Department of Clinical Genetics, Helsinki University Central Hospital, FI-00029 HUS, Finland
\end{abstract}

Email: Sanna Heino - sanna.heino@helsinki.fi; Milja Kaare - milja.kaare@helsinki.fi; Sture Andersson - sture.andersson@hus.fi; Hannele Laivuori* - hannele.laivuori@helsinki.fi

* Corresponding author

Published: 3 November 2008

BMC Medical Genetics 2008, 9:96 doi:10.1 186/147/-2350-9-96
Received: 26 June 2008

Accepted: 3 November 2008

This article is available from: http://www.biomedcentral.com/I47/-2350/9/96

(c) 2008 Heino et al; licensee BioMed Central Ltd.

This is an Open Access article distributed under the terms of the Creative Commons Attribution License (http://creativecommons.org/licenses/by/2.0), which permits unrestricted use, distribution, and reproduction in any medium, provided the original work is properly cited.

\begin{abstract}
Background: Reduced placental perfusion predisposes to the maternal syndrome pre-eclampsia characterized by systemically reduced perfusion. Considerable data support the role of angiogenic factors in the development of the maternal syndrome. Hypoxia-inducible factor (HIF-I) mediates the cellular responses to hypoxia e.g. by promoting angiogenesis.

Methods: Here we studied whether two single nucleotide sequence variants, c. $1744 \mathrm{C}>\mathrm{T}$ that changes residue 582 of HIF- I $\alpha$ from proline to serine (P582S) and c. $1762 \mathrm{G}>\mathrm{A}$ that changes residue 588 of HIF-I $\alpha$ from alanine to threonine (A588T) in the exon 12 of the HIFIA gene, are associated with pre-eclampsia. We studied 108 women with pre-eclampsia in their first pregnancy, and $10 \mathrm{I}$ controls with normotensive pregnancies. Pre-eclampsia was defined as a blood pressure level of at least $140 / 90 \mathrm{mmHg}$ in a woman who was normotensive before 20 weeks of gestation, and proteinuria at least of $0.3 \mathrm{~g}$ per 24 -hour urine collection. The patients and controls were genotyped for variations in the exon 12 of HIFIA gene by sequencing

Results: The frequencies of the c.1744 C>T and c.1762G>A sequence variants were not significantly different between women with pre-eclamptic first pregnancies and women with normotensive pregnancies. In addition, two synonymous variants (c.1740G $>A$ and c. 1800A $>T$ ) were detected at comparable levels in the two groups. All variants were identified in the heterozygous form.
\end{abstract}

Conclusion: The sequence variants in the exon 12 of the HIFIA gene were not associated with pre-eclampsia in the Finnish population.

\section{Background}

Pre-eclampsia, a pregnancy-specific vascular disorder, complicates $3 \%$ of pregnancies, and it may threaten the survival of both mother and baby [1]. The onset and clinical course is unpredictable and there are currently no predictive tests or preventive means available in clinical 
practice. Pre-eclampsia resolves after delivery, which is currently the only existing therapy. It is a heterogeneous disease, commonly mixed presentation of two categories: placental pre-eclampsia with origins primarily in abnormal placental perfusion and maternal pre-eclampsia with origins primarily in pre-existing problems in the mother [2]. Pre-eclampsia shares many common risk factors with atherosclerosis, such as pre-existing hypertension, diabetes, obesity, renal disease and the metabolic syndrome [3]. A large body of evidence also suggests that pre-eclampsia is associated with increased risk of cardiovascular diseases in later life of both mother and baby $[4,5]$. Twin studies have shown that genetic factors account more than 50\% of an individual's susceptibility to pre-eclampsia [6]. Despite intensive research genetic factors predisposing pre-eclampsia are largely unknown $[7,8]$.

Abnormalities in the angiogenic balance have been proposed to as having a major role in the molecular cascade causing maternal endothelial dysfunction and systemically reduced perfusion in pre-eclampsia [9]. Hypoxiainducible factor (HIF-1) is a transcriptional activator that plays important role in physiologic responses to hypoxia, and the pathophysiology of common human diseases such as ischemic cardiovascular disease, cancer, preeclampsia and intrauterine growth restriction (IUGR) [10]. HIF-1 is a heterodimer consisting of an oxygen-regulated HIF1- $\alpha$ subunit and a constitutively expressed HIF1- $\beta$ subunit [10]. The HIF-1 heterodimer recognizes HIFresponse elements within the promoter regions of hypoxia-responsive target genes. More than 100 target genes that are involved in angiogenesis, vascular tone, glucose metabolism, cell proliferation, cell survival and apoptosis are known to be regulated by this mechanism [11]. Under normoxic conditions, the alpha subunit is rapidly degraded by means of ubiquitination and proteosomal degradation $[12,13]$. HIF1- $\alpha$ protein levels are regulated by the von Hippel -Lindau protein, which targets the N-terminal transactivation domain (N-TAD) within the oxygen-dependent degaradation domain (ODD) of HIF1- $\alpha[12,14]$.

Two non-synonymous single nucleotide sequence variants, rs11549465 and rs11549467, in the exon 12 of the HIF1A gene cause amino acid substitution within (rs11549465) or near (rs11549467) the minimal N-terminal transactivation domain (N-TAD) within the ODD that mediates interactions with the von Hippel-Lindau protein, which in turn targets HIF1- $\alpha$ for degradation (Figure 1) [15]. We studied whether these sequence variants, rs11549465 (c.1744 C>T) that changes residue 582 of HIF-1 $\alpha$ from proline to serine (Pro582Ser) and rs11549467 (c.1762 G>A) that changes residue 588 of HIF-1 $\alpha$ from alanine to threonine (Ala588Thr) in the exon 12 of the HIF1A gene, are associated with preeclampsia.

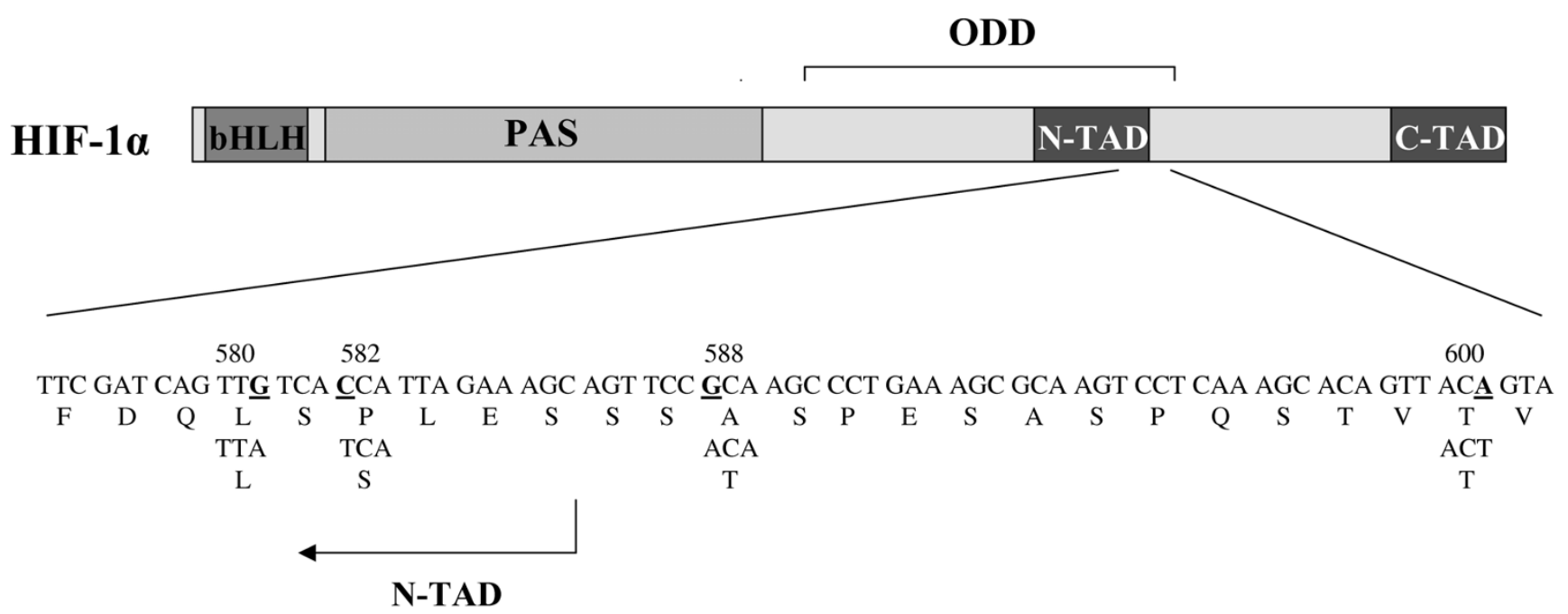

Figure I

Structure of the HIF-I $\alpha$ protein, and polymorphisms identified by sequencing the exon I 2 of the HIFIA gene. bHLH = basic-helix-loop-helix domain, PAS = Per-Arnt-Sim domain, ODD = oxygen dependent degradation domain, $\mathrm{N}-\mathrm{TAD}=$ $\mathrm{N}$-terminal transactivation domain, C-TAD = C-terminal transactivation domain. Rs I I 549465 changes residue 582 of HIF-I $\alpha$ from proline to serine (P582S), and rs I I549467 changes residue 588 of HIF- I $\alpha$ from alanine (A) to threonine (T). Variant rs34005929 is a synonymous change of the last nucleotide of codon 580 encoding a leucine (L). Variant changing the last nucleotide of codon $600(\mathrm{~T})$ is predicted to be a silent polymorphism. 


\section{Methods \\ Patients}

108 women with pre-eclampsia in their first pregnancy, and 101 controls with at least one normotensive pregnancy were included in this study. This is a retrospective analysis of stored DNA samples. The study population has been previously described [16].

Before their first pregnancy, both patients and controls have been healthy and no evidence of renal or autoimmune disease could be detected. Pre-eclampsia was defined using the following criteria; 1) blood pressure (BP) level at least $140 / 90 \mathrm{mmHg}$, and 2) proteinuria at least 0.3 g per 24-hour urine collection [17]. The blood pressure was checked by two measurements with at least 6 hours apart and proteinuria was confirmed after gestation week 20. Pre-eclampsia was defined as severe in 95 women who also fulfilled one or more of the following criteria included in the severity predictors of the National High Blood Pressure Education Working Group: systolic $\mathrm{BP}$ at least $160 \mathrm{mmHg}$, diastolic BP at least $110 \mathrm{mmHg}$, or proteinuria at least $2 \mathrm{~g}$ during any 24-hour urine collection [18].

The blood samples were collected between January 1997 and April 1998 from women who, according to discharge records of the Helsinki University Central Hospital, had had severe pre-eclampsia between 1988 and 1998. The control samples were collected from women with uncomplicated pregnancies who gave birth at the Helsinki University Central Hospital. Patients and controls are of Finnish (Caucasian) origin. This study has been approved by the local ethical review committee and an informed consent was obtained from all the study subjects. The clinical characteristics of the patients are presented in Table 1.

\section{Genotyping}

Genomic DNA was extracted from $10 \mathrm{ml}$ of peripheral blood using a phenol-chlorophorm method. PCR amplification of the exon 12 of the HIF1A gene was performed using forward and reverse primers 5'-CAGAAGCAAAGAACCCAT-3' (F) and 5'-TCAAGAATTTGCGTTAG-3' (R), described by Resar et al. (2005) [19]. The reaction was done in a $50 \mu$ volume containing $70 \mathrm{ng}$ genomic DNA, 30 pmol of each primer, $10 \mathrm{mM}$ Tris- $\mathrm{HCl}, \mathrm{pH} 8.8,1.5 \mathrm{mM}$ $\mathrm{MgCl}_{2}, 50 \mathrm{mM} \mathrm{KCl}$ and $0.1 \%$ Triton X-100, $10 \mathrm{nmol}$ of each nucleotide (dNTP) and 0.75 U Dynazyme polymerase-enzyme (Finnzymes Oy, Espoo, Finland). Polymerase chain reaction conditions were as follows: $4 \mathrm{~min}$ at $94^{\circ} \mathrm{C}$ followed by 35 cycles of denaturation step: $30 \mathrm{~s}$ at $94^{\circ} \mathrm{C}$; annealing step: $30 \mathrm{~s}$ at $49^{\circ} \mathrm{C}$; elongation step: $30 \mathrm{~s}$ at $72^{\circ} \mathrm{C}$; and final extension for $10 \mathrm{~min}$ at $72^{\circ} \mathrm{C}$ terminated the reaction after final annealing. Amplifications were performed in a DNA 2720 Thermal Cycler (ABI, Foster City, CA, USA).

Sequencing of the PCR amplicons were performed using Big Dye Terminator kit (version 3.1) supplied by Applied Biosystems (ABI, Foster City, CA, USA). The reactions were run on an ABI 3730 capillary sequencer according to the manufacturer's instructions.

\section{Statistics and study power}

The minor allele frequencies of the r rs11549465 and rs 11549467 are 0.092 and 0.018 , respectively, in the $\mathrm{CEPH}$ population (Utah residents with ancestry from northern and western Europe) http://www.hapmap.org. Our sample size has $80 \%$ power to detect a relative risk 2.2 for the rs11549465 variant, and a relative risk 2.7 for the rs11549467 variant in the HIF1A gene at a significance level $\alpha=0.05$. Statistical analyses were performed using GraphPad Prism 4 (GraphPad software Inc., CA, USA). The association between the polymorphisms and preeclampsia was estimated by comparing the frequencies in the two study groups. The statistical significance of the different proportions was measured using Fisher's exact test. Parametric and non-parametric tests were used as appropriate for the continuous clinical data. Differences were considered as statistically significant for $P$ values $<0.05$. To determine if genotype frequencies deviate from the the

Table I: Clinical Characteristics

\begin{tabular}{|c|c|c|c|}
\hline & Pre-eclampsia (N = 108) & Controls $(\mathrm{N}=10 \mathrm{I})$ & \\
\hline Variable & Mean $(95 \% \mathrm{Cl})$ & Mean $(95 \% \mathrm{Cl})$ & $P$ \\
\hline Age $(y)$ & $29.5(28.5,30.4)$ & $29.9(28.9 .0,30.9)$ & NS \\
\hline BMI $(\mathrm{kg} / \mathrm{m} 2)$ & $22.6(22.0,23.2)$ & $22.6(21.6,23.5)$ & NS \\
\hline Systolic blood pressure $(\mathrm{mmHg})$ & $17 \mid(168,175)$ & $119(117,121)$ & $<0.0001$ \\
\hline Diastolic blood pressure $(\mathrm{mmHg})$ & $107(105,108)$ & $73(72,75)$ & $<0.0001$ \\
\hline Proteinuria $(g / 24 \mathrm{~h})$ & $7.5(5.9,9.1)$ & & \\
\hline Birth weight (SD) & $-1.5(-1.7,-1.3)$ & $-0.2(-0.4,-0.1)$ & $<0.0001$ \\
\hline Weeks of gestation & $34.5(33.7,35.3)$ & $39.6(39.4,39.9)$ & $<0.0001$ \\
\hline
\end{tabular}

$\mathrm{Cl}=$ confidence interval

$\mathrm{NS}=$ non significant 
Hardy-Weinberg Equilibrium (HWE) a $X^{2}$ test was performed http://www.oege.org.

\section{Results}

As a result of sequencing exon12 of the HIF1A gene and the flanking exon-intron boundaries of HIF1A four exonic sequence variants were detected. All the variants in both patients and controls were detected in a heterozygous state. All four SNP genotype frequencies in both patients and controls were in agreement with Hardy-Weinberg equilibrium $(p>0.05$.)

No statistical differences were shown when comparing the frequencies of the non-synonymous sequence variants, rs11549465 and rs11549467 between patients and controls. Table 2 shows locations of the detected variants, their effect on the protein, and number of alleles in patients and controls. Numbering of the base positions is relative to the adenine in the ATG startcodon of the HIF1A gene.

In addition to two non-synonymous sequence variants, we found two synonymous sequence variants (Figure 1). Variant rs34005929 (c.1740 G>A), a synonymous change of the last nucleotide of codon 580 encoding a leucine, was detected in two patients but in none of the controls. Variant c.1800 $\mathrm{A}>\mathrm{T}$ is changing the last nucleotide of codon 600 (Thr), and is predicted to be a silent polymorphism. This variation was detected in four patients and two controls. According to our knowledge this sequence variant has not been reported in public databases.

\section{Discussion}

In this study performed in the genetically homogenous Finnish population, we found that the allele distribution of the two non-synonymous sequence variants, rs11549465 (c.1744 C>T, Pro582Ser) and rs11549467 (c.1762 G>A, Ala588Thr), in the exon 12 of the HIF1A gene was not different between women with pre-eclamptic first pregnancies and controls with normotensive pregnancies. We also found two synonymous sequence variants in the exon 12 of HIF1A gene: rs34005929 (c.1740 G>A, Leu580Leu) and variant c.1800 A>T (Thr600Thr) which has not previously been reported in public databases.

HIF- $1 \alpha$ is known to play role in the normal development and pathology of placenta as a regulator of responses to hypoxia. Accumulation of HIF-1 $\alpha$ protein in the preeclamptic placentas occurs as a consequence of both increased formation secondary to relative ischemia/ hypoxia and reduced degradation after reperfusion/oxygenation due to proteosomal dysfunction [20]. Overexpression of HIF- $1 \alpha$ protein in placenta contributes to the dysregulation of numerous genes [21]. Abnormalities in the angiogenic balance have been proposed to as having a major role in the molecular cascade causing maternal endothelial dysfunction and systemically reduced perfusion in pre-eclampsia [9], which makes HIF1A an interesting gene in contributing the maternal response to reduced placental perfusion.

Pre-eclampsia originates in the placenta but the target organ is maternal endothelium. Endothelial dysfunction, a central feature in pre-eclampsia, has been suggested to be a part of a more generalized inflammatory reaction [22]. Innate immune response has been linked to the hypoxic response through transcriptional regulation of HIF- $1 \alpha$ by transcription factor NF-кB [23].

Pre-eclampsia increases the risk of future ischemic heart disease [24]. This could be an inherent propensity in these women, or vascular damage may have occurred as a consequence of the pre-eclamptic pregnancy. HIF1A is one of the genes of importance in the pathways mediating the response to ischemia. The rs 11549465 sequence variant was more common in patients who presented with stable exertional angina rather than acute myocardial infarction [25]. These authors suggested that the reduced activity of the variant form of HIF1A could reduce plaque neovascularization and the risk of intraplaque hemorrhage and of subsequent acute myocardial infarction [25].

Table 2: Non-synonymous sequence variants within the oxygen-dependent degradation domain of the HIFIA gene with pre-eclamptic first pregnancies $(N=108)$ and women with normotensive pregnancies $(N=101)$

\begin{tabular}{|c|c|c|c|c|c|}
\hline Variation & Amino acid & No. of alleles in cases & No. of alleles in controls & $P$-value* & OR (95\% Cl) \\
\hline \multicolumn{6}{|c|}{ rsI I549465 (c. I 744C>T) } \\
\hline C allele & Pro582 & 208 & 189 & 0.26 & $0.56(0.23-1.38)$ \\
\hline $\mathbf{T}$ allele & Ser582 & 8 & 13 & & \\
\hline \multicolumn{6}{|c|}{ rsI I 529467 (c.| 762G>A) } \\
\hline G allele & Ala588 & 212 & 199 & 1.00 & $1.25(0.28-5.66)$ \\
\hline$A$ allele & Thr588 & 4 & 3 & & \\
\hline
\end{tabular}

*Fisher's exact test 
The results of the functional studies of the sequence variants in the HIF1A gene in different tissues as well as, the effect of these variants in angiogenesis are inconclusive. The rs11549465 and rs11549467 variants of the HIF1A gene have been shown to have enhanced transcription activities in in vitro studies under both normoxic and hypoxic conditions [26,27]. Rs11549465 variant was associated with increased tumor microvessel density in head and neck cancer [26], and in prostate cancer [27]. The expression of some down-stream genes that are under the transcription control of HIF-1 $\alpha$ (LDH-5, VEGF, GLUT1) was not increased in the presence of the rs1 1549465 variant in non-small cell lung cancer samples studied by immunohistochemistry [28]. In the presence of rs11549465 variant the formation of collaterals in patients with ischemic heart disease was impaired [19].

To the best of our knowledge this is the first study to investigate whether the two non-synonymous sequence variants that lie within or near the N-TAD within the ODD in the exon 12 of the maternal HIF1A gene are associated with the pre-eclamptic phenotype.

These sequence variants are interesting because polymorphisms that reduce the activity of HIF- $1 \alpha$ as a transcriptional activator could underlie pre-eclampsia by causing inadequate placental vascularisation in the early pregnancy which later leads to hypoxia in the placenta. We are not aware of studies comparing the frequency of these sequence variants between the pre-eclamptic placentas and placentas from normotensive pregancies, or studies measuring the HIF- $1 \alpha$ levels in placentas heterozygous of homozygous for these sequence variants.

This retrospective study has several limitations. First, we did not have fetal DNA samples. Consequently, we were neither able to study the effect of fetal/placental genotype nor the maternal fetal genotype interaction. The other limitation is inadequate statistical power to detect small genotypic effects. Under a dominant model, the sample size provides $80 \%$ power to detect a genotype relative risk over 2.2, which is much higher than the risk conferred by the majority of susceptibility genes detected to date for complex disorders. For detection of small genotypic effects studies in larger sample sets are warranted. Further studies are also warranted to elucidate effects of the functional polymorphisms in HIF1A on the pathogenesis of maternal and placental pre-eclampsia. Pre-eclampsia involves complex interaction between placentation, vascular function and maternal metabolism. Thus, research and recognition of genes, such as HIF1A, and thereby biochemical components critical for such interactions increase our understanding of the molecular mechanisms leading from cellular hypoxia to metabolic changes.

\section{Conclusion}

Our data suggest that the sequence variants in the exon 12 of the HIF1A gene are not associated with pre-eclampsia in the Finnish population. The study has inadequate statistical power to detect small genotypic effects. Therefore, this gene should be assessed in bigger studies. Further studies are also warranted to elucidate possible fetal genotypic effects.

\section{Authors' contributions}

SA and HL participated in the study design. MK conducted the sequencing. SH, MK and HL analysed the results. $\mathrm{SH}$, $\mathrm{MK}$, and HL wrote the first draft, and all authors the final version of the manuscript. All authors read and approved the final manuscript.

\section{Acknowledgements}

We would like to express our thanks to Ms. Hanna Nurmi and Ms. Leena Järvinen for technical assistance. This study was supported by the grants of the Academy of Finland, the Finnish Medical Foundation, the Helsinki University Central Hospital, the Päivikki and Sakari Sohlberg Foundation, the Uusimaa Regional Fund of the Finnish Cultural Foundation, and the University of Helsinki.

\section{References}

I. Redman CW, Sargent IL: Latest Advances in Understanding Preeclampsia. Science 2005, 308:1592-1594.

2. Ness RB, Roberts JM: Heterogeneous causes constituting the single syndrome of preeclampsia: $A$ hypothesis and its implications. Am J Obstet Gynecol 1996, 175: I 365-1370.

3. Duckitt K, Harrington D: Risk factors for pre-eclampsia at antenatal booking: systematic review of controlled studies. BMJ 2005, 330:565.

4. Irgens HU, Reisater L, Irgens LM, Lie RT, Roberts JM: Long term mortality of mothers and fathers after pre-eclampsia: population based cohort study Pre-eclampsia and cardiovascular disease later in life: who is at risk? $B M J$ 2001, 323:1213-1217.

5. Barker DJP, Osmond C, Forsen TJ, Kajantie E, Eriksson JG: Trajectories of Growth among Children Who Have Coronary Events as Adults. N Engl J Med 2005, 353:1802-1809.

6. Cnattingius S, Reilly M, Pawitan Y, Lichtenstein P: Maternal and fetal genetic factors account for most of familial aggregation of preeclampsia: a population-based Swedish cohort study. Am J Med Genet Part A 2004, I30A(4):365-37I.

7. Chappell S, Morgan L: Searching for genetic clues to the causes of pre-eclampsia. Clin Sci 2006, I 1 0:443-458.

8. Laivuori $\mathrm{H}$ : Genetic aspects of preeclampsia. Front Biosci 2007 , I 2:2372-2382.

9. Bdolah Y, Karumanchi SA, Sachs BP: Recent advances in understanding of preeclampsia. Croat Med J 2005, 46:728-736.

10. Semenza GL: Hypoxia-inducible factor I: control of oxygen homeostasis in health and disease. Pediatr Res 200I, 49:6I4-6I7.

II. Ke Q, Costa M: Hypoxia-inducible factor-I (HIF-I). Mol Pharmacol 2006, 70: 1469-1480.

12. Maxwell PH, Wiesener MS, Chang G, Clifford SC, Vaux EC, Cockman ME, Wykoff CC, Pugh CW, Maher ER, Ratcliffe PJ: The tumour suppressor protein VHL targets hypoxia-inducible factors for oxygen-dependent proteolysis. Nature 1999, 399:27I-275.

13. Cockman ME, Masson N, Mole DR, Jaakkola P, Chang G, Clifford SC, Maher ER, Pugh CW, Ratcliffe PJ, Maxwell PH: Hypoxia Inducible Factor-alpha Binding and Ubiquitylation by the von HippelLindau Tumor Suppressor Protein. J Biol Chem 2000, 275:25733-2574I.

14. Tanimoto K, Makino Y, Pereira T, Poellinger L: Mechanism of regulation of the hypoxia-inducible factor-I alpha by the von Hippel-Lindau tumor suppressor protein. EMBO J 2000, 19:4298-4309. 
15. Clifford SC, Astuti D, Hooper L, Maxwell PH, Ratcliffe PJ, Maher ER: The pVHL-associated SCF ubiquitin ligase complex: molecular genetic analysis of elongin $B$ and $C, R b x I$ and HIF- I alpha in renal cell carcinoma. Oncogene 200 I, 20:5067-5074.

16. Laivuori H, Kaaja R, Ylikorkala O, Hiltunen T, Kontula K: 677 C->T polymorphism of the methylenetetrahydrofolate reductase gene and preeclampsia. Obstet Gynecol 2000, 96:277-280.

17. Report of the National High Blood Pressure Education Program Working Group on High Blood Pressure in Pregnancy. Am J Obstet Gynecol 2000, I 83:SI-S22.

18. National High Blood Pressure Education Program Working Group Report on High Blood Pressure in Pregnancy. Am J Obstet Gynecol 1990, 163:1691-1712.

19. Resar JR, Roguin A, Voner J, Nasir K, Hennebry TA, Miller JM, Ingersoll R, Kasch LM, Semenza GL: Hypoxia-Inducible Factor I alpha Polymorphism and Coronary Collaterals in Patients With Ischemic Heart Disease. Chest 2005, I 28:787-79I.

20. Rajakumar A, Michael HM, Daftary A, Jeyabalan A, Gilmour C, Conrad KP: Proteasomal Activity in Placentas from Women with Preeclampsia and Intrauterine Growth Restriction: Implications for Expression of HIF- $\alpha$ Proteins. Placenta 2008, 29:290-299.

21. Rajakumar A, Brandon HM, Daftary A, Ness R, Conrad KP: Evidence for the functional activity of hypoxia-inducible transcription factors overexpressed in preeclamptic placentae. Placenta 2004, 25:763-769.

22. Redman CWG, Sargent IL: Pre-eclampsia, the Placenta and the Maternal Systemic Inflammatory Response - A Review. Placenta 2003, 24(Suppl A):S2I-7.

23. Rius J, Guma M, Schachtrup C, Akassoglou K, Zinkernagel AS, Nizet V, Johnson RS, Haddad GG, Karin M: NF-kappaB links innate immunity to the hypoxic response through transcriptional regulation of HIF-Ialpha. Nature 2008, 453:807-8II.

24. Bellamy L, Casas JP, Hingorani AD, Williams DJ: Pre-eclampsia and risk of cardiovascular disease and cancer in later life: systematic review and meta-analysis. BMJ 2007, 335:974.

25. Hlatky MA, Quertermous T, Boothroyd DB, Priest JR, Glassford AJ, Myers RM, Fortmann SP, Iribarren C, Tabor HK, Assimes TL, Tibshirani RJ, Go AS: Polymorphisms in hypoxia inducible factor I and the initial clinical presentation of coronary disease. Am Heart J 2007, I 54: 1035-1042.

26. Tanimoto K, Yoshiga K, Eguchi H, Kaneyasu M, Ukon K, Kumazaki T, Oue N, Yasui W, Imai K, Nakachi K, Poellinger L, Nishiyama M: Hypoxia-inducible factor-I alpha polymorphisms associated with enhanced transactivation capacity, implying clinical significance. Carcinogenesis 2003, 24:1779-1783.

27. Fu XS, Choi E, Bubley GJ, Balk SP: Identification of hypoxia-inducible factor-I alpha (HIF-I alpha) polymorphism as a mutation in prostate cancer that prevents normoxia-induced degradation. Prostate 2005, 63:2/5-22I.

28. Koukourakis MI, Papazoglou D, Giatromanolaki A, Panagopoulos I, Maltezos E, Harris AL, Gatter KC, Sivridis E: C2028T polymorphism in exon 12 and dinucleotide repeat polymorphism in intron I 3 of the HIF-I $\alpha$ gene define HIF-I $\alpha$ protein expression in non-small cell lung cancer. Lung Cancer 2006, 53:257-262.

\section{Pre-publication history}

The pre-publication history for this paper can be accessed here:

http://www.biomedcentral.com/1471-2350/9/96/prepub

\section{Publish with Bio Med Central and every} scientist can read your work free of charge

"BioMed Central will be the most significant development for disseminating the results of biomedical research in our lifetime. "

Sir Paul Nurse, Cancer Research UK

Your research papers will be:

- available free of charge to the entire biomedical community

- peer reviewed and published immediately upon acceptance

- cited in PubMed and archived on PubMed Central

- yours - you keep the copyright
BioMedcentral 